\title{
The Impact of Dragon Boating on Fatigue for Breast Cancer Survivors
}

\author{
Suzanne Denieffe ${ }^{1}$, Margaret Denny ${ }^{2 *}$, Constantino Fiuza-Castineira ${ }^{3}$ \\ ${ }^{1}$ Waterford Institute of Technology, School of Health Sciences, Waterford, Ireland. \\ ${ }^{2}$ University of Maribor, School of Health Sciences, Slovenia. \\ ${ }^{3}$ University of Limerick, Limerick, Ireland. \\ * Corresponding Author: Margaret Denny, University of Maribor, School of Health Sciences, Slovenia. \\ Received date: February 11, 2021; Accepted Date: March 20 2021; Published Date: March 31,2021 \\ Citation: Suzanne Denieffe, Margaret Denny, Constantino Fiuza-Castineira. The Impact of Dragon Boating on Fatigue for Breast Cancer Survivors, \\ J. Psychology and Mental Health Care. 5(1). DOI: 10.31579/2637-8892/103 \\ Copyright: (C) 2021 Margaret Denny, This is an open-access article distributed under the terms of the Creative Commons Attribution License, which \\ permits unrestricted use, distribution, and reproduction in any medium provided the original author and source are credited.
}

\begin{abstract}
Background: Fatigue following treatment for breast cancer has a profound impact on quality of life. Dragon boating is known to be beneficial because of its networking and social function.

Objective: The objective of this study was to explore the effects of dragon boating on fatigue and health related quality of life.
\end{abstract}

Intervention/Methods: Individual and Family Self-Management Theory guided the study. The methodology was a multiple point cohort panel design. Data were collected from breast cancer survivors $(\mathrm{n}=26)$ to measure fatigue, quality of life and upper arm functioning at the beginning of the racing season timepoint $1\left(\mathrm{~T}_{1}\right)$, midway through the programme, timepoint $2\left(\mathrm{~T}_{2}\right)$, and at the end of the dragon boat season, timepoint $3\left(\mathrm{~T}_{3}\right)$.

Results: Fatigue levels fell significantly between $\mathrm{T}_{1}$ and $\mathrm{T}_{2}(\mathrm{p}<.033)$ and from $\mathrm{T}_{2}$ to $\mathrm{T}_{3}(\mathrm{p}<.048)$. Similarly, upper limb functioning improved from $\mathrm{T}_{1}$ to $\mathrm{T}_{2}(\mathrm{p}<.002)$, but showed no significant change between $\mathrm{T}_{2}$ and $\mathrm{T}_{3}(\mathrm{p}<.58)$. Fatigue was significantly related to quality of life at each time point.

Conclusion: While this was a small scale study, the findings suggest that dragon boating appears to have beneficial effects on well-being including reduction of fatigue, which impacts on health related quality of life for women post breast cancer.

Implications for Practice: This study confirms the benefits of dragon boating in upper limb functioning and reduction of fatigue. Health care professionals could advise cancer survivors on the benefits of dragon boating exercise, post cancer treatment.

Keywords: dragon boating; fatigue; breast cancer survivors

\section{Background}

Breast cancer is recognised as the second most common cancer, with over 1.7 million new cases diagnosed each year ${ }^{1}$. The estimated survival rate for breast cancer is five years (over $87 \%$ ) from time of diagnosis. ${ }^{2}$ However, cancer survivors may be left with debilitating side effects. One of the most common of these side effects is cancer related fatigue $(\mathrm{CrF})$, with estimates of prevalence of fatigue ranging from $30 \%$ of survivors experiencing moderate $=$ severe fatigue in survivorship ${ }^{3}$ to $70-90 \%$ experiencing fatigue. ${ }^{4} \mathrm{CrF}$ can be defined as a distressing, persistent, subjective sense of physical, emotional, and/or cognitive tiredness or exhaustion related to cancer or cancer treatment that is not proportional to recent activity and interferes with usual functioning. ${ }^{5} \mathrm{CrF}$ has been described in the literature as a multidimensional construct having physical, cognitive and emotional factors ${ }^{6}$ and impacts on quality of life, as $\mathrm{CrF}$ may also predict shorter overall cancer survival. ${ }^{7-8}$
Hence, there is a need to use evidence based interventions to help with the management and treatment of this fatigue. Exercise, which includes personalised physical activity, is now generally accepted as a primary intervention for the management of $\mathrm{CrF}^{5,9,10-11}$. A recent meta-analysis of 42 studies, ${ }^{12}$ carried out on 3816 cancer survivors reported moderate intensity aerobic exercise was safe and effective for reducing $\mathrm{CrF}$ (SMD, $0.32,95 \%$ CI 0.22 to 0.40 ). Similar results were reported by Tian,Lu, Lin et al, ${ }^{13}$ who reported exercise to be more effective than conventional care in improving fatigue in cancer survivors (SMD, $-0.22,95 \%$ CI -0.39 to 0.04). The benefits of exercise are therefore verified by a number of randomised controlled studies (RCTs) and systematic reviews, ${ }^{8-9,}$, 14-15 which showed a positive effect on fatigue reduction.

Nonetheless, it seems that breast cancer survivors are remaining physically inactive. ${ }^{16}$ The Clinical Oncology Society of Australia released a position statement calling for exercise to be prescribed as part of routine cancer care. In addition, cancer patients should be referred to exercise 
specialists with experience in cancer care ${ }^{17}$. Leclerc et al ${ }^{18}$ and Swartz et $\mathrm{al}^{19}$ highlight the benefits of multi-disciplinary interventions for breast cancer survivors that have a community based focus. They suggest that such rehabilitation programmes create a public health impact and enhance accessibility to more cancer survivors.

While exercise to reduce fatigue can be undertaken on an individual and/or group basis, it has been shown that group exercise in breast cancer survivors is successful, in part because of the networking and social function of such exercise groups. ${ }^{20}$ Dragon boating is one such community and group based exercise form that has been shown to be popular in women post breast cancer. ${ }^{21}$ Dragon boating is thought to have originated as a Chinese ritual during the 4 th Century BC. As described by the International Dragon Boat Federation ${ }^{21}$ it involves strenuous, repetitive upper body exercise as 18-22 team-mates propel a 12 metre long boat through the water and may be led by a drummer to keep the paddling rhythm regular. Dragon boat racing has been used with breast cancer survivors since 1996, with over 210 breast cancer dragon boat teams now in existence over 23 different countries. ${ }^{21}$

Initial literature on dragon boating had concerned itself with the possible harm that boating could do to women who had surgery for breast cancer and concluded that it did no harm. ${ }^{22-25}$ Further studies on women who participated in dragon boat racing showed that it led to feelings of camaraderie, team spirit, a sense of renewed fitness, health, enhanced self-confidence and control of one's life. ${ }^{26-31}$ Hence, while studies have shown that dragon boat racing has many beneficial effects on quality of life, ${ }^{32-35}$ there is limited quantitative research that studied the impact of dragon boat racing for cancer survivors on fatigue and quality of life..$^{26,35}$

\section{Theoretical Framework}

The theoretical framework informing the study was the Individual and Family Self-Management Theory ${ }^{36}$. This theory proposes that selfmanagement involves individuals or families assuming responsibility for the management of chronic conditions, by purposefully performing a cluster of behaviours. Self-management in this theory is seen as a complex dynamic phenomenon consisting of three dimensions: context, process, and outcomes. Outcomes can be proximal or distal ${ }^{36}$. Table 1 details the application of the theory elements to the study and identification of the variables to be measured.

\begin{tabular}{|l|l|}
\hline Theory Elements & Elements Application \\
\hline Context & $\begin{array}{l}\text { Condition: Post Cancer Survivors: } \\
\text { Physical Social Environment: Dragon Boating } \\
\text { Individual: Adults post cancer }\end{array}$ \\
\hline Process & $\begin{array}{l}\text { Knowledge and Beliefs : Exercise and Cancer } \\
\text { Outcome expectancy- Self Regulation: Participation in Dragon Boating } \\
\text { Social Facilitation: Dragon Boat Peer Group }\end{array}$ \\
\hline $\begin{array}{l}\text { Outcomes } \\
\text { Proximal }\end{array}$ & $\begin{array}{l}\text { Self-Management Behaviour: Ongoing participation in Dragon Boating } \\
\text { Outcomes Distal }\end{array}$ \\
Study Objectives & $\begin{array}{l}\text { Quality of Life: measured by EORTC - } \\
\text { Health Status : Fatigue measured by FACT-F } \\
\text { Upper Limb functioning- Measured by Quick-DASH }\end{array}$ \\
\hline
\end{tabular}

Table 1: Application of the Individual and Family Self -Management Theory to the Study

The aim of the study was to explore the effects of dragon boating on fatigue, limb functioning and quality of life in survivors of breast cancer.

The research objectives were to:

1. Assess the impact of dragon boating on participants' fatigue levels over a boating season using the FACT-F;

2. Examine participants' perceptions of upper limb functioning over a boating season using the Quick Dash;

3. Examine the changes in the participants' health related quality of life over a boating season using the EORTC.

A prospective observational design was employed to meet the study aim and objectives. This design involves the sampling of a group of participants and measures variables of interest at more than one point in time $^{37}$.

\section{Study Sample}

The population of interest were women who had been treated for breast cancer and who were taking part in Dragon Boat Racing. The sampling method was purposive, with inclusion criteria being that the person had a previous diagnosis of cancer. There were no exclusion criteria. Ethical approval was obtained from the relevant research ethics boards. Following Ethical Review Board approval, women taking part in the dragon boating activity across three Dragon Boating Groups in the South of Ireland, were approached by the researchers and invited to a brief presentation about the study. The participants received a research information sheet and were invited to participate.

\section{Data Collection}

Date were collected through the use of validated self-report instruments to measure fatigue and HRQOL over the course of a Dragon boating season- March to October, with time-point $1 ; \mathrm{T}_{1}$, at the beginning of season, time-point $2 ; \mathrm{T}_{2}$, midway and time-point $3 ; \mathrm{T}_{3}$, on season completion. The T1, T2 and T3 assessments were collected from all study participants at the same time.

\section{Fatigue}

Fatigue was assessed using the Functional Assessment of Cancer FatigueTherapy Questionnaire. ${ }^{38}$ This is a 13 item scale. Scoring Responses to the items are on a 5- point scale ranging from ' 0 ' (not at all) to ' 4 ' (very much). Scores on items are summed to give a single total fatigue score. Downie et $\mathrm{al}^{39}$ suggested a cut-off score of 9-22 for mild fatigue, 23-36 for the presence of moderate fatigue and above 37 for severe fatigue. Cella et al (2002) identified 3.0 as a clinical important difference change for this scale. 


\section{Health Related Quality of Life}

HRQOL was assessed using the EORTC-QLC Core 30. The European Organisation for Research and Treatment of Cancer Quality of Life Questionnaire C30 Version 3 (EORTC QLQ-C30), was specifically designed for use in cancer patients and clinical research. ${ }^{40}$ It consists of 30 items that make up both multi-item scales and single item measures. ${ }^{40}$ Scales used in this study included the global quality of life scale and the five functional scales (physical, role, emotional, cognitive and social).

A high score on the global QOL scale represents a high level of functioning and quality of life. According to Fayers and Machin ${ }^{41}$ the global health status / QOL scale should be used as the overall summary measure for HRQOL status. In accordance with this recommendation, the global HR QOL score was used to interpret overall level of health related QoL in the study.
Limb Functioning

Perceived upper limb functioning was assessed using the Quick Disabilities of the Arm, Shoulder and Hand (Quick DASH), Questionnaire. ${ }^{42}$ This is an 11 item questionnaire that asks about arm symptoms as well as assessing ability to perform certain activities (Scored $0-4)$. The assigned values for all completed responses are summed and averaged. A higher score indicates greater disability. The minimal clinically important difference (MCID) has been identified as 8.0points.

Reliability of the Tools

The reliability of the tools was assessed using Cronbach's Alpha (Table 2).

\begin{tabular}{|l|c|c|}
\hline Scale & Number of items & Cronbach's $\boldsymbol{\alpha}$ \\
\hline FACT-F & 13 & 0.91 \\
\hline QuickDASH & 11 & 0.80 \\
\hline $\begin{array}{l}\text { EORTC } \\
\text { subscales }\end{array}$ & & \\
\hline Global health status & 2 & 0.90 \\
\hline Physical Functioning & 5 & 0.70 \\
\hline Role Functioning & 2 & 0.90 \\
\hline $\begin{array}{l}\text { Emotional } \\
\text { Functioning }\end{array}$ & 4 & 0.80 \\
\hline Cognitive Functioning & 2 & 0.60 \\
\hline Social Functioning & 2 & 0.80 \\
\hline
\end{tabular}

Table2: Reliability of the Tools

\section{Socio-Demographic Information}

Socio-demographic information was also obtained including age, marital status and duration of time since completion of treatment.

\section{Dragon Boating Procedure}

The dragon boating exercise was conducted in boats which held 10 rows of two per seat with a steer person in the back and a drummer / caller in the front.

\section{Study findings}

Recruitment took place over an 8 month period (1/3/16 - 15/10/2016). Thirty-eight women completed questionnaires at T1, 40 completed at T2 and 39 at T3. Only 26 women completed questionnaires at all three time points and there were 23 women with only two data time points. This group were referred to as the incomplete data group. Statistical differences between those women who provided completed data (questionnaires for $\mathrm{T}_{1}, \mathrm{~T}_{2}$, and $\mathrm{T}_{3}$ points were compared with those women who provided data at only $T_{1}$ or $T_{2}$, using independent two tailed tests for the continuous variables of age and fatigue. Using Chi square analysis, the retained $(n=26)$ and the incomplete data group $(n=23)$ were not statistically different with respect to age $(\mathrm{t}(47)=0.7, \mathrm{p}=.48)$, fatigue $(\mathrm{t}(47)=0.67, \mathrm{p}=.5$. Three dragon boating groups were involved in the study with 5 participants from group one, 11 from group 2 and 10 from group three.

The socio-demographic and clinical characteristics of the study participants who were retained at all time-points are summarized in Table 3 . The total number of participants retained was 26 women, with ages ranging from 34-70 years (mean 54, SD 8.3). Most participants were in a relationship $(61 \%, \mathrm{n}=21)$, with $46 \%(\mathrm{n}=12)$ in paid employment. Regarding cancer diagnosis, $38.6 \%$ reported being stage 1 on diagnosis, with the remainder having a stage 2 cancer on diagnosis. All women had surgery $(100 \%)$, with $80.6 \%$ received radiotherapy, $67.8 \%$ received chemotherapy while $82 \%$ received hormone therapies, for example, aromatase inhibitors or tamoxifen. None of the women in the study reported a recurrence, metastasis or other change during the season. Of the sample, it was the first season of racing for $60 \%, 19.4 \%$ had attended the previous season while $20.4 \%$ had participated in three or more seasons. Most women $(90.0 \%)$ participated in one on-water training session per week.

\begin{tabular}{|l|l|l|}
\hline Variable & & \\
\hline Age (years) & Range 34-70 & Mean 54.5 (SD 8.3) \\
\hline Marital Status & n (\%) & \\
Married & $16(61.5)$ & \\
Widowed & $2(7.7)$ & \\
Separated & $2(7.7)$ & \\
Never Married & $5(19.2)$ & \\
\hline Employment & n $(\%)$ & \\
Full-time & $5(19.2)$ & \\
\hline
\end{tabular}




\begin{tabular}{|l|l|l|}
\hline Part-time & $7(26.9)$ & \\
Unemployed & $4(15.4)$ & $9(34.6)$ \\
Retired & $1(3.8)$ & \\
\hline Housewife & n $(\%)$ & $7(26.9)$ \\
\hline Time since treatment & $7(26.9)$ & \\
$4-12$ months & $9(34.6)$ & $3(11.5)$ \\
$13-24$ months & Stage 1 - 38.6\% & \\
$25-60$ months & Stage 2- 61.4\% & \\
\hline 61 months & Surgery- 100\% & \\
\hline Cancer Stage at Diagnosis & Radiation Therapy- 80.6\% Chemotherapy- 67.8\% & \\
\hline Treatments Received & Hormonal Therapy-78\% \\
& Non-specified Treatments- 4\% \\
\hline
\end{tabular}

\section{Table 3: Socio-demographic Characteristics}

\section{Fatigue}

The presence of fatigue, at the 3 time points, early in the racing season $T_{1}$, midway through season $T_{2}$ and at end of racing season $T_{3}$ was examined using the FACT- F, with a cut-off score of 9 indicating the presence of fatigue. As can be seen in Table 4 fatigue lessened over the timeframe of the study. When examined, using a Repeated Measures (RM)- ANOVA, mean fatigue scores differed significantly between time points $(\mathrm{F}(2,24)=4.5, \mathrm{p}=.005)$. Post-hoc tests using a Bonferroni correction revealed that fatigue improved between $\mathrm{T}_{1}$ and $\mathrm{T}_{2}(13.5+/-11.4$ vs $11.5+/-9.8$ respectively), which was statistically significant $(\mathrm{p}=.033)$. Fatigue scores at $\mathrm{T}_{3}(10.1+/-9.3)$ were also significantly different to the scores at $\mathrm{T}_{1}(\mathrm{p}=.015)$ and $\mathrm{T}_{2}(\mathrm{p}=.048)$.

Spearman's correlation co-efficient was used to examine the relationships between fatigue level, age, and time since completion of treatment. No significant relationships were identified between age and fatigue and fatigue $\left(\mathrm{T}_{1}-.074, \mathrm{~T} 2-0.66, \mathrm{~T} 3-.066\right)$ or time since completion of treatment and fatigue ( -.074$)$. Likewise no relationship was found between stage of cancer on diagnosis or treatment type and fatigue levels.

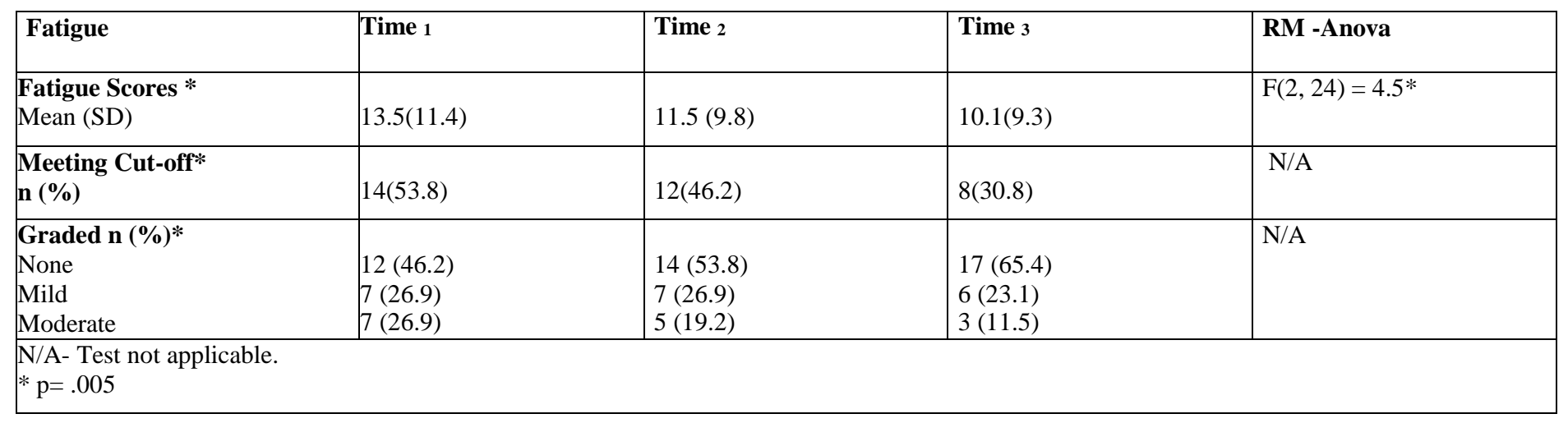

Table 4: Fatigue Measured using FACT-F

\section{Health Related Quality of Life}

Global HRQOL at the 3 time points, early in racing season $T_{1}$, midway through season $T_{2}$ and at end of racing season $T_{3}$ was examined using the Global Quality of Life Scale from the EORTC QoL C30 questionnaire. When examined, using a RM- ANOVA, Global HRQOL mean scores did not differ significantly between time points $\left(\mathrm{T}_{1} 73.0\right.$ (SD16.6), $\mathrm{T}_{2}$ 74.3(SD 15.3), $\mathrm{T}_{3}$ 74.65(SD15.8), $\left.\mathrm{F}(2,24)=1.74, \mathrm{p}=.19\right)$.

Likewise functional levels (physical, role, emotional, social and cognitive) showed no differences in levels between the time points when examined using a RM- ANOVA (Table 5).

\begin{tabular}{|l|l|l|l|}
\hline QLQ-C30 Sub-scales & $\begin{array}{l}\mathbf{T}_{1} \\
\text { Mean (SD) }\end{array}$ & $\begin{array}{l}\text { Time 2 } \\
\text { Mean (SD) }\end{array}$ & $\begin{array}{l}\text { Time 3 } \\
\text { Mean (SD) }\end{array}$ \\
\hline $\begin{array}{l}\text { Global Quality of } \\
\text { Life* }\end{array}$ & $73.0(16.6)$ & $74.3(15.3)$ & $74.65(15.8)$ \\
\hline Functional Scales & & & \\
Physical & $81.6(12.7)$ & $83.7(15.8)$ & $85.8(12.6)$ \\
Role & $82.1(5.8)$ & $86.0(6.0)$ & $88.2(26.5)$ \\
Emotional & $78.8(22.1)$ & $76.1(22.3)$ & $78.4(20.3)$ \\
Social & $84.9(19.4)$ & $84.9(21.2)$ & $82.2(23.1)$ \\
Cognitive & $80.7(9.9)$ & $80.5(4.4)$ & \\
\hline$* \mathrm{~F}(2,24)=1.74$ & & \\
\hline
\end{tabular}


Pearson's correlation co-efficient was used to examine the relationships between fatigue level and global HRQOL at each time point and identified significant negative correlations $\mathrm{T}_{1}-0.855(0.000), \mathrm{T}_{2}-0.807(0.000)$ and $\mathrm{T}_{3}-0.651(0.000)$.

\section{Upper Limb Functioning}

Upper limb functioning at the 3 time points, was examined using the Quick DASH questionnaire. As can be seen in Table 6 limb functioning improved over the time-frame of the study, whereby lower scores indicate better functioning. When examined using a RM-ANOVA mean scores differed significantly between time points $(\mathrm{F}(2,24)=8.1, \mathrm{p}=0.002)$. Posthoc tests using a Bonferroni correction revealed that upper limb functioning improved between $\mathrm{T}_{1}$ and $\mathrm{T}_{2}(5.92+/-6.0$ vs 4.5 +/-5.5 respectively) which was statistically significant $(\mathrm{p}=0.002)$. Upper limb functioning scores at $\mathrm{T}_{3}(4.12+/-4.9)$ were also significantly different to the scores at $\mathrm{T}_{1}(\mathrm{p}=.002)$ but not to the scores at $\mathrm{T}_{2}(\mathrm{p}=.58)$. However these change did not reflect a clinically important difference.

\begin{tabular}{|l|l|l|l|l|}
\hline Upper Limb Functioning & Time 1 & Time 2 & Time 3 & ANOVA \\
\hline $\begin{array}{l}\text { Quick DASH Scores } \\
\text { Mean (SD) }\end{array}$ & $5.9(6.0)$ & $4.5(5.5)$ & $4.12(4.9)$ & $\mathrm{F}(2,24)=8.1^{*}$ \\
\hline $\mathrm{p}=0.002$ & & & & \\
\hline
\end{tabular}

Table 6: Upper Limb Functioning Measured using Quick DASH

\section{Discussion on Findings}

In line with the literature that suggests the beneficial effects of exercise for cancer survivors in terms of reducing fatigue, ${ }^{3-4,}$, 12-13,14-15 the findings of this study suggest that dragon boating, as an exercise mode, also appears to have beneficial effects. Dragon boating is becoming increasingly popular worldwide and as a community based group exercise option offers potential as an intervention for cancer survivors. Hence, in line with the self-management theory ${ }^{36}$ dragon boating provides a condition specific physical and social environmental intervention that can have a risk reductive effect on cancer recurrence and therefore a protective effect on health.

Given that cancer-related fatigue is a common long term side effect for cancer survivors ${ }^{3-4}$ the clinically important difference change is an important finding. It was seen in the results of this study that fatigue levels fell significantly between $\mathrm{T}_{1}$ (early in boating season) and $\mathrm{T}_{2}$ (mid-way through season) and again a significant fall in fatigue scores between $\mathrm{T}_{2}$ and $\mathrm{T}_{3}$ (end of season). Therefore, having an impact on a distal health status wellbeing outcome ${ }^{36}$.

This study confirms the finding of Ray et $\mathrm{al}^{26}$ who also found a decrease in fatigue over a dragon boating season. What is important to consider is that in this study over $50 \%$ of the women were fatigued at the commencement of the dragon boating season, with $25 \%$ experiencing moderate fatigue. Even on completion of the season over $30 \%$ were still experiencing fatigue.

Unfortunately, assessment and management of $\mathrm{CrF}$ is not always been incorporated into routine care ; this deficiency needs to be addressed particularly as $\mathrm{CrF}$ may also predict shorter overall cancer survival. ${ }^{7}$ Despite the prevalence of $\mathrm{CrF}$, it is still often undertreated and health care professionals often do not understand the extent of the distress and functional impairment such a disabling side effect can have on patients. ${ }^{32,8}$ As $\mathrm{CrF}$ is often seen as an inevitable part of cancer and its treatment, clinicians and patients may not see the need to manage it. ${ }^{32}$ Health professionals therefore need to be fully cognisant of the fatigue levels that their patients may be experiencing and explore this with them and discuss possible interventions. Nurses and other health professionals have a responsibility to explore exercise and other interventions to reduce fatigue and to identify those who may not be engaging in appropriate interventions for their fatigue. It is highly recommended $10,11,43-44$ that health professionals ensure that personalised physical activity programmes are integrated in rehabilitation interventions for cancer survivors .
Global health related quality of life scores did not change significantly over the time periods but were generally quite high. This finding is in line with that of Ray et $\mathrm{al}^{26,36}$ where the changes in health related quality of life did not represent a clinically significant change. It could be that the women participating in dragon boating are relatively well in survivorship, and hence evidence good levels of health related quality of life. However, quality of life was still negatively correlated with fatigue levels, in that as fatigue levels were higher and quality of life scores were lower.

This study examined upper arm functioning from the perspective of whether dragon boating could have beneficial effects as perceived by the participants. Findings showed that there was a significant difference between scores for limb functioning at $\mathrm{T}_{1}$ when compared to time- $\mathrm{T}_{2}$ but was not a clinically important difference (Mintken et al 2009). This could suggest that dragon boating brings about an improvement but only to a certain extent and thus the need for further study, perhaps using objective measurements rather than a reliance on subjective report measures. It could also suggest that limb functioning was not a clinical problem for this group and hence was not going to achieve a clinically significant change.

\section{Limitations}

The current study was a descriptive exploratory study with a small sample size. Cofounders, such as degree of participation in the dragon boating or other exercise taken were not controlled for. Hence, generalisations cannot be made.

Not having a control group was also a limitation of the study. Further research, under more controlled conditions and perhaps using a control group may be helpful. The inclusion of process elements of the SelfManagement theory could be included in future research in this area, which was beyond the scope of this study. Ideally, a research study should include randomisation and controlling for the characteristics of the sample. In addition, a longitudinal study including collection of data outside of the non-dragon boating season could be undertaken.

\section{Conclusion}

This study set out to examine the impact of dragon boating on fatigue levels and quality of life in women breast cancer survivors over a dragon boating season using the Individual and Self-Management Theory to inform the study. While this was a small scale study, the findings suggest that dragon boating, as a rehabilitation intervention, appears to have beneficial outcomes, in helping to reduce reported fatigue and improve limb functioning in breast cancer survivors life. 


\section{References}

1. Ferlay J1, Soerjomataram I, Dikshit R, et al. (2015). Cancer incidence and mortality worldwide: Sources, methods and major patterns in GLOBOCAN 2012. Int J Cancer ; ( 1):136-5 Doi: 10.1002/ijc.29210. Epub 2.

2. Cancer Research UK.( 2018). Cancer Statistics. Accessed August 10 .

3. Wang XS, Zhao F, Fisch MJ, O'Mara AM, et al. (2014). Prevalence and characteristics of moderate to severe fatigue: A multicentre study in cancer patients and survivors. Cancer. ; 120 (3):425-432.

4. Prue G, Rankin J, Allen J, et al. (2006). Cancer-related fatigue: A critical appraisal. Eur J Canc.; 42 (7): 846-863.

5. (2018). NCCN Clinical Practice Guidelines in Oncology (NCCN) Breast Cancer. National Comprehensive Cancer Network. Accessed August 10.

6. Berger AM, Mooney K, Alvarez-Perez A, et al. (2015). CancerRelated Fatigue,Version 2. 2015. J Natl Compr Canc Netw. :1 3:1012-1039.

7. Groenvold M., Petersen MA.,, Idler E. et al. (2007). Psychological distress and fatigue predicted recurrence and survival in primary breast cancer patients. Breast Cancer Res. Treat. :105, 209-219).

8. Nekhlyudov L., Greene S. M., Chubak J. (2013). Cancer research network: using integrated healthcare delivery systems as platforms for cancer survivorship research. Journal of Cancer Survivorship,:7(1):55-62.

9. Cramp F, Byron-Daniel J. (2012). Exercise for the management of cancer-related fatigue in adults. Cochrane Database Systematic Review; 14(11): CD006145.

10. Pennington KP, McTiernan A. (2018). The role of physical activity in breast and gynaecologic cancer survivorship. Gynecol Oncol .; 149(1):198-204

11. Stubblefield MD. The underutilization of rehabilitation to treat physical impairments in breast cancer survivors. PM $R$. 2017;9:S317- S323.

12. Dennett AM, Peiris CL, Shields N, et al. (2016). Moderateintensity exercise reduces fatigue and improves mobility in cancer survivors: a systematic review and meta-regression. Journal of Physiotherapy. ; 62(2): 68- 82. DOI: 10.1016/j.jphys.2016.02.012.

13. Tian L, Lu HJ, Lin L, et al. (2015). Effects of aerobic exercise on cancer-related fatigue: a meta-analysis of randomized controlled trials. Supportive Care in Cancer. ; 24(2): 969-983.

14. Adraskela K, Veisaki E, Koutsilieris M, et al. (2017). Physical exercise positively influences breast cancer evolution. Clin Breast Cancer.;17: 408-417.

15. Wirtz P, Baumann FT. (2018). Physical Activity, Exercise and Breast Cancer - What Is the Evidence for Rehabilitation, Aftercare, and Survival? A Review Breast Care (Basel). ,13(2)2:93-101.

16. Lucas AR, Levine BJ, Avis NE. (2017). Posttreatment trajectories of physical activity in breast cancer survivors. Cancer.;123;27732780.

17. Cormie P, Adams D, Atkinson M, et al. (2018). Clinical Oncology Society of Australia Position Statement in Cancer Care, (Sydney), Accessed:December 7.

18. Leclerc AF, Foidart-Dessalle M, Tomasella M, et al. (2017). Multidisciplinary rehabilitation program after breast cancer: benefits on physical function, anthropometry and quality of life. Eur J Phys Rehabil Med.;53: 633-642.

19. Swartz MC, Lewis ZH, Lyons EJ, et al. (2017). Effect of homeand community-based physical activity interventions on physical function among Cancer Survivors: A Systematic Review and Meta-Analysis. Arch Phys Med Rehabil .;98;1652-1665.

20. Kim BH, Wallington SF, Makambi KH, et al. (2015). Social networks and physical activity behaviors among cancer survivors: Data from the 2005 health information national trends survey. $J$ Health Communicat .; 20(6):656-662.

21. International Dragon Boat Federation. (2018). The dragon boat: history and culture. Accessed: December 2.

22. Harris SR, Niesen-Vertommen S.L..(2000). Challenging the myth of exercise-induced lymphedema following breast cancer: a series of case reports. Journal of Surgical Oncology. : 74(2); 95-99.

23. Lane K, Jespersen D, McKenzie D. (2005). The effect of a whole body exercise programme and dragon boat training on arm volume and arm circumference in women treated for breast cancer. European Journal of Cancer Care .; 14 (4): 353-358.

24. McNeely ML, Campbell KL, Courney K.S, et al. (2009). Effect of acute exercise on upper-limb volume in breast cancer survivors: a pilot study. Physiotherapy Canada.; 61(4): 244-251.

25. Ray HA, Verhoef MJ.( 2013). Dragon boat racing and healthrelated quality of life of breast cancer survivors: A mixedmethods evaluation. BMC, Complementary and Alternative Medicine.; 13(1): 205.

26. Guinto-Advinto ML, Zavala M. (2017). "I am a complete woman": Dragon boat and breast cancer survival. Journal of Sports Psychology.; 26 ( 3): 12-16.

27. Sabiston CM, McDonough MH, Crocker PR. (2007). Psychosocial experiences of breast cancer survivors involved in a dragon boat program: Exploring links to positive psychological growth. J Sport Exercise Psychol.; 29(4):419-438.

28. Parry DC. (2008). The contribution of dragon boat racing to women's health and breast cancer survivorship. Qual Health Res; $18,(2): 222-233$.

29. McDonough MH, Sabiston CM, Ullrich-French. (2011). The development of social relationships, social support and posttraumatic growth in a dragon boating team for breast cancer survivors. Journal of Sport and Exercise Psychology.; 33(5): 627-648.

30. McKensie DC. (1998). Abreast in a boat- a race against breast cancer. CMAJ .; 59(4): 376- 378.

31. Mitchell T, Nielsen E. (2002). Living life to the limits: dragon boaters and breast cancer. Can Woman Stud.; 21(3):50-57.

32. Unruh AM, Elvin N. (2004). In the eye of the dragon: women's experience of breast cancer and the occupation of dragon boat racing. Can J Occup Ther; 71(3):138-149.

33. Hadd V, Sabiston CM, McDonough MH et al. (2010). Sources of stress for breast cancer survivors involved in dragon boating: examining associations with treatment characteristics and selfesteem. Sport Exercise Psychology.; 19(7):1345-1353.

34. Culos-Reed SN, Shields C, Brawley LR. (2005). Breast cancer survivors involved in vigorous team physical activity: psychosocial correlates of maintenance participation. Psychooncology.; 14:594-605.

35. Ryan P, \& Sawin K. (2009). The individual and self-management theory: Background and perspectives on context, process, and outcomes. Nursing Outlook;(57):217-225

36. Salkind N (2010) Encoyclopedia of Research Design. Accessed. $2 / 16$

37. Yellen SB, Cella D, Webster K, et al. (1997). Measuring fatigue and anaemia related symptoms with the Functional Assessment of Cancer Therapy (FACT) measurement system. Journal of Pain and Symptom Management.; 13: 63-74.

38. Downie FP, Mar Fan HG, Houede Tchen N. (2006). Cognitive function, fatigue, and menopausal symptoms in breast cancer patients receiving adjuvant chemotherapy, evaluation with patient 
interview after formal assessment. Psycho-oncology.; 15: 921930.

39. Aaronson NK.( 1993). The EORTC QLQ C-30, A quality of life instrument for use in international clinical trials in oncology. Quality of Life Research; 2: 51-59.

40. Fayers PM, Machin D. (1995). Sample size, how many patients are necessary? British Journal of Cancer.;72: 1-9.

41. Hudak PL, Amadio PC, Bombardier C. (1996). Development of an upper extremity outcome The Disabilities of the Arm, Shoulder\&Hand Score - QuickDASH - Orthopaedic Scores measure: the DASH (disabilities of the arm, shoulder \& hand) [corrected]. The Upper Extremity Collaborative Group (UECG). Am J Ind Med. 29(6):602-8. Erratum in: Am J Ind Med 1996 30(3):372.

42. American Cancer Society (2017). Cancer related fatigue. Accessed:November 6, 2018.

43. Zimmer P, Baumann FT, Oberste M, et al. (2017). Influence of personalized exercise recommendations during rehabilitation on the sustainability of objectively measured physical activity levels, fatigue, and fatigue-related biomarkers in patients with breast cancer. Integr Cancer Ther; 17(2):306-311.

44. Cella D, Eton DT, Lai JS, Peterman AH, Merkel DE. (2002). Combining anchor and distribution-based methods to derive minimal clinically important differences on the Functional Assessment of Cancer Therapy (FACT) anemia and fatigue scales. J Pain Symptom Manage. Dec;24(6):547-561.

45. Mintken P.E., Glynn P., Cleland J.A. (2009). Psychometric properties of the shortened disabilities of the Arm, Shoulder, and Hand Questionnaire (QuickDASH) and Numeric Pain Rating Scale in patients with shoulder pain. J Shoulder Elbow Surg.; 18(6): 920-926. 